\title{
O MENOR E SUA INSERÇÃO NO MERCADO DE TRABALHO
}

\section{ARTIGO DE REVISÃO}

LIMA, Betânia Cristina Geber dos Santos de ${ }^{1}$

WARSZAWIAK, Ana Cristina Zadra Valadares ${ }^{2}$

LIMA, Betânia Cristina Geber dos Santos de. WARSZAWIAK, Ana Cristina Zadra Valadares. $\mathbf{O}$ menor e sua inserção no Mercado de Trabalho. Revista Científica Multidisciplinar Núcleo do Conhecimento. Ano 05, Ed. 02, Vol. 01, pp. 93-107. Fevereiro de 2020. ISSN: 2448-0959, Link de acesso: https://www.nucleodoconhecimento.com.br/lei/mercado-de-trabalho

\section{RESUMO}

O trabalho precoce pode ser percebido como processo benéfico e de melhoramento na vida do adolescente, desde que a sua finalidade seja atingida e não ultrapasse os limites estabelecidos. Assim, o adolescente pode se tornar um cidadão de bem, buscando realizar os seus sonhos e uma melhor qualificação e experiência profissional. Assim, frente a inserção do jovem no mercado de trabalho, existem leis, decretos, regulamentos, portarias; enfim, diversos instrumentos legais que normatizam a relação e que oferecem as diretrizes estruturais e orgânicas para seu exercício de acordo com o interesse de constituição da sociedade. Neste elo, o objetivo deste estudo foi descrever sobre a inserção do menor no mercado de trabalho. Para a coleta de dados foram realizadas buscas sistematizadas em literaturas dispostas nas bases de dados da Internet, como Revista e Bibliotecas Virtuais da SciELO, Periódicos da CAPES, além de pesquisa na Biblioteca Online disponível no site da Faculdade Educacional da Lapa - FAEL. Portanto, é preciso uma

\footnotetext{
${ }^{1}$ Especialista em Direito do Trabalho; Graduada em Direito.

2 Doutorado em Direito. Mestrado em Direito. Especialização em MBA Direito Tributário. Graduação em Direito.
} 
fiscalização mais severa por parte das autoridades competentes, além de um desenvolvimento urgente de programas educativos e profissionais, que possam atuar de forma concreta para se inserir de forma digna o menor no campo de trabalho.

Palavras-Chave: Menor, primeiro emprego, legislação.

\section{INTRODUÇÃO}

O presente estudo visou descrever sobre a inserção do menor no mercado de trabalho apontando alguns limites em sua jornada de trabalho trazidos pela legislação e pela condição peculiar deste contingente na observância e garantia da Constituição Federal. Onde, é preciso observar o Princípio da Proteção Integral com vistas ao desenvolvimento físico, psíquico e biológico do adolescente, frente a sua a sua característica especial e diferenciada anunciadas ainda por meio de políticas públicas com prioridade jurídica e social.

Silva e Costa (2019) apontam que o trabalho do menor está disciplinado no Estatuto da Criança e do Adolescente, na Consolidação das Leis do Trabalho, na Lei no 10.097/00 que se refere ao trabalho do menor aprendiz, na Constituição Federal de 1988 e demais normas, incluindo as internacionais, como as expedidas pela Organização Internacional do Trabalho - OIT. Nestes termos, percebe-se que em nosso ordenamento é aceitável a inserção do menor/adolescente no mercado de trabalho, porém, com suas devidas restrições.

O trabalho precoce pode ser percebido como processo benéfico e de melhoramento na vida do adolescente, desde que a sua finalidade seja atingida e não ultrapasse os limites estabelecidos. Assim, o adolescente pode se tornar um cidadão de bem, buscando realizar os seus sonhos e uma melhor qualificação e experiência profissional (SILVA; COSTA, 2019).

Diante do exposto, portanto, justifica-se o estudo sobre a temática em questão ao entender que a inserção do menor no mercado de trabalho pode ser considerada como um processo de oportunidades, desde que munido de deveres e obrigações 
legais frente as determinações de jornada de trabalho e suas possíveis consequências no âmbito jurídico.

Contudo, para nortear este estudo, foi escolhido como objetivo geral: Descrever sobre a inserção do menor no mercado de trabalho. E como objetivos específicos, descrever os aspectos gerais do trabalho do menor no Brasil; delinear a inserção do menor no mercado de trabalho e ainda apresentar os direitos legais do menor no mercado de trabalho.

Para a coleta de dados foram realizadas buscas sistematizadas em literaturas dispostas nas bases de dados da Internet, como Revista e Bibliotecas Virtuais da SciELO, Periódicos da CAPES, além de pesquisa na Biblioteca Online disponível no site da Faculdade Educacional da Lapa - FAEL.

\section{O TRABALHO DO MENOR NO BRASIL: ASPECTOS HISTÓRICOS E GERAIS}

$\mathrm{Na}$ história do Brasil, não só as crianças e adolescentes portuguesas pobres foram convidados, atravessadamente do consumo da sua força de trabalho, para constituição e desenvolvimento do país. A população infanto-juvenil negra e indígena também foi contida às rigidezes do trabalho prematuro, desde o Brasil Colônia até a modernidade, construindo a estrutura de produção conforme os ciclos econômicos gerados pelo país (Pau-Brasil, café, cana-de-açúcar entre outros), num processo de repartição de riquezas que nutriu a disparidade social, pois os interesses da Coroa no Brasil e dos Portugueses que aqui chegaram eram puramente econômicos, de espoliação, e por meio da escravidão estabeleceu-se no país um exemplar de aversão pela vida (FALEIROS, 1995).

Com a expansão e implante da economia industrial capitalista no país, depois do momento escravista, a circunstância de disparidade social, provocada desde a chegada dos portugueses, não foi decomposta, e a situação do trabalho infanto-juvenil ainda era fato para muitas crianças e adolescentes. Nesse momento industrial, muitas 
foram às crianças e adolescentes brasileiros e estrangeiros entrados no sistema vitorioso das fábricas e oficinas, assim como afiança Moura (2004, p. 262):

[...] a aparição do trabalho infanto-juvenil retratou-se como reflexo do desprezível molde de vida da família proletária, catalogada em salários medíocres e em indicadores de custo de vida muito elevados. O monopólio do trabalho se dava através da pressão salarial do trabalhador adulto de sexo masculino; da exploração da mão-de-obra feminina, uma vez que a remuneração de meninas e de adolescentes de sexo feminino caracterizava a dupla discriminação de sexo e de idade; refletindo-se de forma clara a ocorrência categórica de que a infância e a adolescência eram decisão do empresariado em diminuir os gastos de produção.

Não somente as indústrias, mas também no mercado informal era utilizada a força de trabalho infanto juvenil, como na venda de utensílios pelas ruas da cidade. As crianças e adolescentes eram assistidas enquanto trabalhavam junto às praças e às portas das igrejas, lubrificando sapatos, vendendo jornais, e até na construção civil. Outros, para sobreviverem, recorriam à atividade de esmolar, assaltar e roubar (MOURA, 2004).

As crianças e adolescentes minados pelas ruas das amplas cidades, como São Paulo, cogitavam a falta de base econômica, social e política vivente nos centros industriais. As pessoas que migravam do campo, de outros estados, outras cidades ou de outros países, em procura de melhores aspectos de vida, acumulavam-se em cortiços, favelas, construções clandestinas e até debaixo de pontes. Essa conciliação lavra a ideia da falta de famílias estruturadas, desprovidas de contribuições sociais, financeiras, culturais e até psíquicas que impelem as crianças e adolescentes para a mendicidade, expondo-os à criminalidade ou à delinquência (SILVA, 2009).

Igualmente como na história mundial, em nosso país, a valorização da criança e do adolescente está fortemente alistada à classe social que ocupa. Deste modo, a preponderância do trabalho infanto-juvenil em limites brasileiros, estabelece-se alicerçado em um pensamento de segregação, o qual se manifesta mais visível, 
quando a evolução legislativa é examinada sobre o tema. Anteriormente a ilustre Lei Áurea, não havia qualquer princípio protetor ao trabalho do menor, até porque, numa economia basicamente agrícola, a mão-de-obra utilizada era escrava, ou seja, desprovida de escolha, desamparada pelo Direito. As crianças negras, por exemplo, assim como seus pais, não se diferiam de um artefato, predicado de seu dono. Sendo assim, trabalhavam como se adultos fossem (SILVA, 2009).

Esse trabalho precoce exercido por pessoa que ainda não está preparada para exercer determinadas atividades laborais, também pode ser entendido como o aproveitamento da mão de obra, no âmbito familiar é utilizada para ajudar aumentar a renda e suprir as necessidades básicas, quando a situação tem um terceiro que aproveita do labor infanto-juvenil, consideradas como "patrão", este visa obter lucro, pagando salários ínfimos e oferecendo serviços não condizentes à idade da pessoa empregada. Conforme entendimento da legislação brasileira vigente, quando não atingir a idade mínima permitida para o trabalho, a mão-de-obra infanto-juvenil é proibida, de modo que qualquer ocupação ou emprego que prejudique a saúde, educação, ou que interfira no desenvolvido físico, mental ou moral da pessoa envolvida deve ser considerado ilegal (SILVA, 2010).

Vilani (2007) assinala que a contemporânea prole de jovens brasileiros foi nascida e criada sob o valente modelo constitucional da doutrina da proteção absoluta, de forma cristalina dentro de art. 227 da Carta Federal de 1988. Diz-se valente modelo constitucional pelo seu efeito, onde, temos uma das estruturas jurídicas mais avançadas do mundo contemporâneo em termos de abrigo dos direitos das crianças e adolescentes. Porém, tão perturbador quanto o nosso passado nefasto do monopólio da mão de obra infantil é o episódio de que, de aspecto tão lenificado, aquele elevado molde constitucional venha se perdendo para se transfigurar em realidade nessas mais de duas décadas de proclamação da Constituição.

O padrão de desenvolvimento da produção imperante na Inglaterra da Revolução Industrial, em meados do século VIII, difundiu fortes tentáculos a propósito da economia brasileira, em completa consolidação do procedimento de conquista portuguesa, quando era cômoda a escravidão de crianças, mulheres e homens de 
origem negra, da qual o Brasil se fez dependente economicamente por mais de três séculos (VILANI, 2007).

Após o término da Primeira Guerra Mundial, em Paris, no ano de 1919, realizou-se a Conferência da Paz, a qual teve como anseio a criação de uma bancada, composta por emissários de governos, trabalhadores e empregadores, para estudo e laboração de nomeadas propostas para uma legislação internacional do trabalho. Esta bancada/comissão cunhou uma Carta do Trabalho que sobrepujava nove títulos orientadores da política internacional para as relações trabalhistas, dentre eles estava a abolição do trabalho infantil. Cabais orientações ordenadas por tal comissão puxaram toda a base para o Tratado de Versalhes, o qual deu existência a Organização Internacional do Trabalho - OIT -, em 1919 (CENPEC, 2001).

No ano de 1924, a Assembleia da Liga das Nações, aprovou a Declaração de Genebra dos Direitos da Criança, o primeiro instrumento internacional de proteção aos menores. Porém, não conseguiu lograr extenso reconhecimento pelos países por não ter força vinculativa aos Estados. Somente com a Declaração Universal dos Direitos do Homem, no ano de 1948, aprovada pela Assembleia Geral das Nações Unidas, verifica-se a evolução na percepção sobre a proteção à criança (VIEIRA, 2006).

A convenção Internacional dos Direitos da Criança foi aprovada no dia 20 de novembro de 1989 foi o efeito de uma diligência conjunta entre vários países. A convenção estabelece-se durante dez anos, em uma raia quanto à garantia de seus direitos e também direito a sua proteção, tendo em vista que congregaram em um mesmo documento legal, códigos de expressões brandas, acomodando-se aos mais distintos fatos, apresentando as futuras políticas legislativas dos Estados - Partes. Entretanto, a grande provocação versa em deliberar direitos universais para as crianças (VIEIRA, 2006).

Esta Convenção sempre teve como objetivo, estimular os países membros a inserirem o desenvolvimento harmônico e integral da individualidade de suas crianças, beneficiando seu crescimento em um ambiente familiar saudável. A fim de que se 
volvessem capazes para conviverem em sociedade e serem educadas com espírito de dignidade, paz, tolerância, solidariedade, liberdade e igualdade.

\section{INSERÇÃO DO MENOR NO MERCADO DE TRABALHO}

Sobre a relação do jovem com o trabalho há leis, decretos, regulamentos, portarias; enfim, diversos instrumentos legais que normatizam a relação e que oferecem as diretrizes estruturais e orgânicas para seu exercício de acordo com o interesse de constituição da sociedade. As referências ao jovem e ao adolescente podem ser encontradas em instrumentos gerais da legislação, como a Constituição Federal do Brasil, de 1988, ou em instrumentos específicos, como as leis que regulamentam iniciativas de políticas públicas, como a Lei que normatiza as ações Programa Nacional do Primeiro Emprego - PNPE (BRASIL, 2005).

O crescimento do desemprego e a deterioração das condições de inserção no mercado de trabalho no Brasil são apontados como uma das principais consequências da crise econômica e social das duas últimas décadas. As profundas transformações pelas quais vem passando a economia brasileira se materializam nas intensas e rápidas alterações na composição da força de trabalho e na estrutura do emprego (BRAGA, RODARTE, 2006).

Nesse contexto Braga e Rodarte (2006) afirmam ainda que os jovens em idade legal de trabalhar tornam-se um dos segmentos mais frágeis na disputa por um posto de trabalho em meio ao elevado excedente de mão-de-obra e a perda de oportunidades ocupacionais em empregos regulares. A crescente dificuldade de inserção ocupacional para este grupo etário pode, assim como para os adultos, ser vista da perspectiva da desorganização do mercado de trabalho brasileiro, isto é, do agravamento da situação de desemprego, do crescimento do número de trabalhadores sem vínculo empregatício institucionalizado e dos elevados níveis de informalidade.

Entretanto, a falta de perspectiva para esta faixa da população, que não raro, não compõe a população economicamente ativa, nem frequenta o sistema escolar, 
destaca-se como um dos principais fatores de desagregação social no período atual. O sistema escolar não os acolhe em função da má qualidade do ensino público, ou não os interessa, dada a inadequação dos programas escolares oferecidos às camadas populares, enquanto o mercado de trabalho os expulsa (BRAGA, RODARTE, 2006).

As dificuldades de ingresso no mercado de trabalho têm favorecido certo alongamento dos estudos e também a protelação da constituição de um núcleo familiar. Ou seja, diante do adiamento do ingresso no mercado de trabalho e a consequente dificuldade em conquistar certa autonomia financeira, os jovens tendem a permanecer mais tempo na casa dos pais, resistem à ideia de constituição de uma nova família e retardam a saída da escola, tida como uma alternativa frente ao desemprego (DA SILVA, 2010).

Permanecer na escola parece significar aos jovens uma estratégia para enfrentar a competitividade no mercado de trabalho, contudo, há o momento em que estes precisam se dedicar ao trabalho, e ingressam no mundo do trabalho, que na maioria das vezes não é muito fácil, e tão pouco satisfatório.

\section{LEGISLAÇÃO}

Em nosso país, a Constituição Federal, do ano de 1988, a Consolidação das Leis Trabalhistas (CLT), de 1942, a Convenção sobre os Direitos da Criança, de 1989, a Lei de Diretrizes e Bases da Educação (LDB), de 1996, o Estatuto da Criança e do Adolescente (ECA), de 1990 e a Lei Orgânica de Assistência Social (LOAS), de 1993, conduzem sobre a circunstância da criança e do adolescente. A Constituição Federal de 1988, em seu artigo 227, escolheu a criança e o adolescente como anteposição absoluta. Adiciona, no inciso XXXIII, do artigo $7^{\circ}$, o impedimento de trabalho perigoso, noturno ou insalubre os menores de dezoito e de qualquer trabalho os menores de dezesseis anos, salvo na condição de aprendiz, a partir de 14 anos. Ainda na Constituição Federal, o inciso I, o Art. 208, afiança ensino fundamental obrigatório e gratuito, inclusive sua doação gratuita para todos os que a ele não tiverem ingresso na idade própria (ZADRA, 2008). 
O Estatuto da Criança e do Adolescente (ECA) estabelece ainda, mecanismos como os Conselhos dos Direitos e Tutelares, tratados pelos Artigos 88, 131 e 132, para a garantia dos direitos. Esses Conselhos são corresponsáveis no processo de erradicação do trabalho infantil. A Lei №. 9.394, de 20 de dezembro de 1996 Diretrizes e Bases da Educação (LDB), em seu Art. 87, § 5º, estabelece que serão ajustadas todas as diligências com ônus ao progresso dos circuitos escolares públicas urbanas de ensino fundamental para o regime de escolas em tempo integral (BRASIL, 1996).

A Lei ㄲo. 8.742, de sete de dezembro de 1993 - Orgânica de Assistência Social (LOAS), em seu Art. $2^{\circ}$, ressalta a proteção à família, à criança e ao adolescente em situação de risco social. As Convenções da Organização Internacional do Trabalho (OIT) №. 138, que estabelece a idade mínima de admissão ao emprego, e №. 182, sobre as piores formas de trabalho infantil e a ação imediata para sua eliminação, ambas aprovadas pelos Decretos Legislativos №. 178 e 179, publicados do Diário Oficial da União em 15 de dezembro de 1999 e ratificadas em 20 de janeiro de 2000 (ZADRA, 2008).

Uma das legislações mais avançadas do mundo no presente assunto abordado é a do Brasil, sendo que a idade mínima para a entrada no mercado de trabalho é de 16 anos, antes dessa idade não poderá exercer qualquer trabalho, com exceção do trabalhador na condição de aprendiz a partir de 14 anos. Porém, observa-se a existência de um conflito entre a lei e a realidade dos fatos, porque somente a norma jurídica não resolve os problemas sociais e educacionais existentes em nosso país. É patente a grande desigualdade entre o povo brasileiro, muitas famílias pobres por não terem uma qualidade de vida estável permitem que seus filhos trabalhem para aumentar a renda familiar (SILVA, 2010).

É degradante uma criança ou adolescente trabalhar em atividades, já citadas acima, onde ficam expostos aos riscos que atividade oferece, e pior, antes de estarem preparados para o trabalho. A desigualdade, a pobreza, a exclusão social e além de fatores de ordem cultural pode-se dizer que são as principais características do trabalho de crianças e adolescentes, e a exploração afronta de forma direta os direitos 
assegurados, e mais, ofende um princípio fundamental que é o da compostura da pessoa humana, sendo este um dos alicerces do Estado Democrático de Direito da recente carta magna (SILVA, 2010).

Silva (2010), relata ainda que foi a partir da Constituição Federal de 1988 que o trabalho de crianças e adolescentes passou a ser combatido formalmente como um problema, e sendo sujeitos de direitos, o Brasil assumiu dar prioridade absoluta, tanto na esfera nacional como internacional. O labor nessa fase da vida não só afronta os direitos humanos, como também a dignidade da pessoa humana, vale lembrar, que quando crianças e adolescentes assumem algum tipo de trabalho, são afastados do ensino e estão sujeitos a situações de perigo e danosas à sua saúde, e que quando adultos, terão uma baixa expectativa de vida.

A Constituição Federal - CF de 88 veda em seu discurso a distinção de salários, a distinção de destreza de funções e ainda os critérios de admissão frente a idade (art. $7^{\circ}, \mathrm{XXX)}$ e proibiu o trabalho noturno, perigoso ou insalubre, aqueles com idade inferior a 18 anos e sobretudo, qualquer trabalho aqueles com idade inferior a 14 anos, salvo na condição de aprendiz (art. 7º, XXXIII). Restabeleceu ainda, a idade mínima de 14 anos para o trabalho do menor, fixada em 12 anos pela Constituição de 1967 (BRASIL, 1988).

Como diretriz constitucional, foi editada a Lei ํㅛ 8.069 de 13/07/90, esta fundou o Estatuto da Criança e do Adolescente (ECA). Sendo hoje em dia, a habilitação judiciária nacional mais aperfeiçoada dentro do que rege o amparo à criança e ao adolescente, onde, seus artigos de 60 a 69 são destinados ao Direito à Profissionalização e à Proteção ao Trabalho. A Emenda Constitucional no 20 de 15/12/98, deu ao art. 7º, inciso XXXIII da Lei Maior a seguinte redação: proibição do trabalho noturno, perigoso ou insalubre a menores de 18 (dezoito) anos e de qualquer trabalho a menores de 16 (dezesseis) anos, salvo na condição de aprendiz, a partir de 14 (quatorze) anos. Assim, os dispositivos da CLT e do ECA que são contrárias as demarcações de idade instituídos pela EC № 20/98 permanecem revogados (BRASIL, 1990). 
De forma geral, a Lei n 8.069/1990 (Estatuto da Criança e do Adolescente), veio regular a disposição refreada na Constituição Federal, da garantia de todos os direitos fundamentais das crianças e dos adolescentes. Esse Estatuto surgiu com o intento de resguardar os direitos dos menores, hasteando Conselhos Nacionais, Estaduais e Municipais, dos Fundos a ele vinculados, dos Conselhos Tutelares, da tipificação penal e da capitulação de infrações administrativas das condutas violadoras de algumas normas nele previstas, na busca da efetividade destas que, por proporcionarem interesse público e social, não poderiam estar incluídas entre as normas programáticas, precisando encontrar efetividade e aplicação plena (FERRARO, 2000).

\section{DIREITOS DO MENOR NO MERCADO DE TRABALHO}

Antes de adentrar no liame que dita os direitos do menor no mercado de trabalho, se faz necessário discorrer um pouco sobre alguns aspectos gerais do trabalho infantil.

A pobreza, a desigualdade social, os expedientes naturais diminuídos, anexo à falta de políticas públicas, foram alguns fatores assinalados como motivos instigantes para a prática do trabalho infantil. Para as crianças se coligarem ao mercado de trabalho, não necessitava, respectivamente, todos esses fatores juntos. A miséria por si só, já as impele para aqueles, que, com alegação de que são solidários, transformam-se em precursores de mão-de-obra barata (ZADRA, 2008).

No domínio geográfico, os estudiosos distinguem o problema, para regiões carentes de países subdesenvolvidos, aonde as famílias são abundantes, com reduzidas rendas, o que direcionam as crianças a se coagirem no ato de contribuição financeiramente em casa, como o enfoco de origem do trabalho infantil. Contudo, existe a necessidade de se analisar outros ares, individualmente em nosso país, quando lá no princípio da colonização do Brasil, os filhos pequenos dos negros e dos índios eram, facilmente, ajuntados ao tradicional das tarefas do cultivo, nas atividades de casa além de ajudantes das mais variadas funções a serem cumpridas naquela época, com o intento de auxiliar no mantimento da família (DANTAS, 2007). 
Entretanto, no mundo contemporâneo, este elemento ainda se manifesta de maneira apavorante. Bastam contemplarmos o convívio urbano com atenção para percebemos que existem espalhadas por aí muitas crianças que necessitam vender balas ou doces nas praças, em portas de estabelecimentos ou na pior das hipóteses como mendigas nos semáforos. O Brasil, no tentame de fazer frente a essa esfinge social, com atos efetivos, tem cunhado programas sociais exclusivos, como por exemplo, o programa bolsa família, que visa melhorar as condições para revertera atual condição de crianças e adolescentes nas ruas, trazendo-os para dentro de seus lares novamente, além de conseguir mantê-las na escola, através de um apoio financeiro aos seus pais (DANTAS, 2007).

O ensaio das autoridades de impedirem oficialmente este tipo de acontecimento social, que é o trabalho infantil, instituindo legislação peculiar, ainda não é satisfatório para sua resolução. A justiça emprega seus mecanismos subjacentes para penitenciar as pessoas responsáveis pela coação infantil e impedir a ação das empresas que se prevalecem deste tipo de contratação, mas o que se vê na realidade é que as penas são brandas e em sua maioria não chegam a serem aplicadas, nem as próprias famílias são castigadas por isso (CONCEIÇÃO, 2011)

Conforme elencado no artigo $1^{\circ}$ da Lei 10.748/2003, o Programa Nacional do Primeiro Emprego vincula-se as ações que regem a à promoção da inserção do menor no mercado de trabalho e sua escolarização. Fortalecer a participação da sociedade neste processo de formação de políticas também é uma promoção prevista, bem como ações que gerem trabalho e renda, como o objetivo sobretudo, de promover a criação de vagas de emprego para estes jovens, preparando-os para o mercado de trabalho e ocupações similares que gerem renda além da qualificação do menor para o mercado de trabalho (BRASIL, 2003).

A idade mínima do jovem para que este possa ingressar no mercado de trabalho, obedece a alguns termos constitucionais elencados no artigo $7^{\circ}-\mathrm{XXXIII}$, no referido artigo existem dois parâmetros de idade, sendo: a proibição de qualquer trabalho a menores de dezesseis anos; e a permissão do trabalho na condição de aprendiz a 
partir de quatorze anos. Com isso, a CLT, seguiu o mesmo direcionamento constitucional, bem como o Estatuto da Criança e do Adolescente (BRASIL, 1988).

Cabe ressaltar que a garantia à educação e sua permanência na escola é assunto relevante, onde as normas jurídicas garantem não apenas a compatibilidade entre o estudo e o trabalho, porém, o trabalho não pode prejudicar o estudo e o acesso à escola, sua permanência e seu bom desempenho escolar. A Constituição Federal, ao conferir a amparo absoluto aos adolescentes em condições de trabalhadores, de igual modo, garantiu-Ihes acesso à escola (POCHMANN, 2007).

O ECA com mesmo direcionamento preceitua a proibição de trabalhos que venham prejudicar a frequência e permanência escolar. Assim, a CLT não podia tratar o assunto de forma diferente, vindo a reproduzir o que foi disposto pelo ECA, além disso, atribui aos empregadores a concessão do tempo que for preciso para frequência escolar (POCHMANN, 2007).

Já no contrato de trabalho surgem obrigações mútuas que devem ser desempenhadas pelas partes contratantes. A obrigação principal do empregado é prestar serviços, por outro lado, a obrigação do empregador é pagar salário. E é justamente por essa razão que deve existir um sistema legal que confira limites à duração da jornada de trabalho do trabalhador (MANUS, 2004).

A jornada de trabalho se refere ao tempo em que o empregado está trabalhando ou esperando ordens, ou seja, à disposição do empregador, conforme contrato de trabalho. A fixação de horas extras é proibida para o trabalhador na condição de menor, bem como a proibição de celebrar acordo para prorrogação da jornada de trabalho. Exceto na hipótese de compensação de horas (MANUS, 2004).

Cabe dizer que o trabalho noturno é vedado pela CLT, esta justifica-se, por ser o trabalho noturno considerado como desgastante, ao contrário daquele que é realizado durante o dia, vindo a ocasionar maior cansaço e exigir grande esforço mental para que se cumpra suas tarefas. Contribuindo ainda para prejuízos na ordem familiar e social, pela falta de harmonia entre os períodos de descanso e os hábitos da vida. 
Visto que ao adolescente, deve ser assegurada à frequência escolar (NASCIMENTO, 2003).

Com relação à insalubridade, vale destacar o conceito exposto no artigo 189 da CLT, que determina que serão consideradas atividades ou operações insalubres aquelas que, por sua natureza, condições ou métodos de trabalho, exponham os empregados a agentes nocivos à saúde. Do mesmo modo que a vedação anterior, a CLT (artigo 405, I) e o Estatuto (artigo 67, II), proíbem o trabalho insalubre aos menores de dezoito anos, provando mais uma vez a intenção do legislador de proteger o indivíduo em formação, resguardando sua integridade e saúde (NASCIMENTO, 2003).

A CLT determina ainda, conforme elencado em seu artigo 190, que é de jurisdição do Ministério Público do Trabalho e Emprego, regulamentar este tópico e tomar medidas para caracterização da insalubridade, bem como limites e meios de proteção. Desse modo, o MPTE, por meio da portaria no $3.214 / 78$ e ainda da NR-15 visam disciplinar quais atividades são consideradas insalubres nas quais não se consente 0 trabalho de adolescentes (DANTAS, 2007).

Elencados no artigo $7^{\circ}$ da CF, em conformidade com os artigos 67, I da CLT e 67, II do ECA, o trabalho quando é de forma correta considerado perigoso, também é proibido aos menores. Entende-se por atividade perigosas, aquelas onde se utilizam produtos inflamáveis ou explosivos, bem como aquelas onde há a manipulação de fios de alta tensão elétrica (MARTINS, 2005).

Cabe destacar como direitos principais do jovem aprendiz o salário mínimo, as a rescisão contratual, férias, o FGTS no percentual de $2 \%$ e ainda auxilio transporte. $O$ jovem deverá cumprir as exigências incumbidas do trabalho ao qual está disposto a exercer, executando com zelo e compromisso as tarefas necessárias (VIANNA, 2012).

Contudo, não se pode deixar de destacar que o funcionamento do mercado de trabalho é ainda desfavorável ao menor que tenta ingressar nesta nova etapa de sua vida. Com isso, observa-se que a fida presença de um excessivo contingente, o menor vai ocupando cada vez menos espaço, haja vistas o meio competitivo frente a adultos 
capacitados. Por este desnivelamento, é que foram pensadas ações governamentais para a inserção do menor no mercado de trabalho (POCHMANN, 2007).

\section{CONSIDERAÇÕES FINAIS}

Diante do que foi abordado, percebe-se que ao longo dos anos, nossa legislação vem ampliando os direitos do menor no mercado de trabalho, bem como culminando em uma série de mudanças, com vistas a expandir a proteção desta classe trabalhista.

Os responsáveis legais dos menores, bem como os empregadores devem se atentar para que estes não trabalhem em locais que prejudiquem a sua frequência escolar, seu desenvolvimento físico, psíquico, social e moral. A proteção do trabalho do menor é imprescindível e deve ser efetiva seguindo os aspectos formais elencados nas diversas legislações.

A falta de condições financeiras das famílias é a maior abrangência para a busca de emprego por parte dos menores, e estes precisam ser respeitados. Sabe-se que para muitas famílias o ideal seria que o adolescente permanecesse com tempo livre somente para o estudo, porém, no caso do nosso país, isso é muito difícil, tendo em vista a necessidade que a maior parte das famílias tem, de que é preciso que seus filhos ajudem no sustento do lar.

Sabe-se também, que o jovem anseia sua inserção no mercado de trabalho, entretanto, muita das vezes isso não é uma missão fácil. A inclusão no campo profissional harmoniza o aprendizado e o crescimento, e ainda a responsabilidade e autoconfiança, tanto profissional quanto pessoal.

Ao discutir esta temática, surge um estímulo que em meio a muitos direitos criados e alcançados, ainda existem inúmeras dificuldades e descasos que pairam esta senda. A inserção do menor no mercado de trabalho é uma inquisição que anseios e se demonstra em destaque em nosso país, uma vez que se encontra em alerta com vistas as obrigações legais, contudo ao considerar profundamente o contexto, da 
mesma forma muitos outros debates podem ser inseridos, ademais, outras contribuições se vinculam a este cenário.

Deste modo, no decorrer do estudo, verificou-se que o contexto relacionado ao menor e o mercado de trabalho, são espaços ainda a serem trilhados com mais vigor e responsabilidade pela sociedade em geral, que de forma subjetiva reproduz objetivamente dilemas de cunho social cada vez mais alarmantes. Porém, enquanto protagonistas de suas próprias caminhadas, os jovens acompanham maciçamente estas mudanças.

Algumas dificuldades vivenciadas pelos jovens frente a inserção no mercado de trabalho vão sendo vencidas ao passo que os mesmos buscam por seu primeiro emprego, este rol vem ganhando destaque cada vez mais visível nos últimos anos. Neste contexto, trata-se ainda de um problema social que reflete no estilo de ser de cada um ator desta geração. Portanto, é preciso uma fiscalização mais severa por parte das autoridades competentes, além de um desenvolvimento urgente de programas educativos e profissionais, que possam atuar de forma concreta para se inserir de forma digna o menor no campo de trabalho.

De modo geral, afirma-se a necessidade de um pensamento positivo com vistas a melhor inserção do menor no mercado de trabalho com os prestígios que the conferem. Onde, os próprios empreendimentos frente a esta inclusão irão continuar reproduzindo o papel de trabalho intenso, visto que à medida que muitos conseguem se inserir, outros muitos se veem cada vez mais excluídos. Eis então os empenhos frente aos seus direitos e o reforçamento para seu alcance.

\section{REFERÊNCIAS}

BRASIL. Lei no 8.069, de 13 de julho de 1990. Dispõe sobre o Estatuto da Criança e do Adolescente e dá outras providências. Diário Oficial [da] União, Poder Executivo, Brasília, DF, 16 de jul. 1990. 
BRASIL. Ministério do Trabalho e Emprego. Portal do Trabalho e Emprego Programa Nacional de Estímulo ao Primeiro Emprego - PNPE. Apresentação. Brasília - DF, 2005 Disponível em www.mte.gov.br/pnpe/apresentacao.asp.

BRASIL. Presidência da República. Lei no 9.394, de 20 de dezembro de 1996. Estabelece as diretrizes e bases da educação nacional. Brasília - DF, 1996

BRASIL. Constituição da República Federativa do Brasil. Brasília: Senado Federal, 1988

CONCEIÇÃO, Maria Dalva Dias. Trabalho infantil no Brasil. In: Âmbito Jurídico, Rio Grande, XIV, n. 87, abr 2011. Disponível em: http://www.ambitojuridico.com.br/site/index.php?n_link=revista_artigos_leitura\&artigo_id=9338

DA SILVA, Luciene Gomes; CAVALCANTE, Marta Teles. Programa jovem aprendiz sobre uma perspectiva pedagógica: reflexões acerca da inserção no mercado de trabalho de adolescentes e seus embates na vida escolar. Semana internacional de pedagogia. Debates e embates na formação docente. Alagoas, 2014

DANTAS, Nozângela Maria Rolim. Programa de Erradicação do Trabalho Infantil: Uma análise da função e qualificação dos monitores da jornada ampliada da cidade de João Pessoa. Programa de Pós-Graduação em Educação - 171 f. Dissertação de Mestrado (Título de Mestre em Educação). Universidade Federal da Paraíba. João Pessoa - PB, 2007.

FALEIROS, V. P. Infância e processo político no Brasil: In: PILOTTI, F; RIZZINI, I. (Orgs.). A arte de governar crianças: a história das políticas sociais, da legislação e da assistência a infância no Brasil. Rio de Janeiro: Amais, 1995.

FERRARO, V. A. L. Direito à proteção do menor. Ciências Jurídicas. Londrina, v. 1, n. 1, p. 41-52, mar. 2000.

MANUS, Pedro Paulo Teixeira. Direito do trabalho. 6. ed. São Paulo: Atlas, 2001.

MARTINS, Sérgio Pinto. Direito do trabalho. 21. ed. São Paulo: Atlas, 2005. 
NASCIMENTO, Nilson de Oliveira. Manual de Trabalho do Menor. São Paulo: LTr, 2003

POCHMANN, M. Situação do jovem no mercado de trabalho no Brasil: um balanço dos últimos $\mathbf{1 0}$ anos. São Paulo: 2007. Disponível em: $<$ http://www.emater.mg.gov.br/doc/intranet/upload/TRANSFORMAR_LEITURA/situa \%C3\%A7\%C3\%A30_do_jovem_no mercado_de_trabalho.pdf $>$.

SILVA, C. C. A exploração do trabalho infantil e do menor de $\mathbf{1 6}$ anos e a legislação do Brasil. Trabalho de conclusão de curso apresentado à Universidade Estadual de Mato Grosso do Sul - UEMS. Monografia de Graduação (título de Bacharel em Direito) - 67 f. Universidade Estadual de Mato Grosso do Sul. Parnaíba - MS, 2010.

SILVA, S. V. M. Trabalho Infantil: aspectos sociais, históricos e legais. OLHARES PLURAIS - Revista Eletrônica Multidisciplinar. Maceió - AL, v. 1, n. 1, 2009

SILVA, Andreza Bispo da; COSTA, Antonia Valdelucia. Políticas e Programas Públicos que Oportunizam a Inserção do Jovem no Mercado de Trabalho. Id on Line - Revista Multidisciplinar e de Psicologia. v.13, n. 43, p. 967-981, 2019

VIEIRA, J. M. Reflexões sobre a transição para a vida adulta: o caso do Estado de São Paulo. In: Encontro Nacional de Estudos Populacionais. Desafios e oportunidades do crescimento zero. Caxambu, MG, 2006. Disponível em: http://www.abep.nepo.unicamp.br/encontro2006/docspdf/ABEP2006_237.pdf

VILANI, Jane Araújo dos Santos. A questão do trabalho infantil: mitos e verdades Inclusão Social.,v. 2, n. 1, p. 83-92, out. 2006/mar. 2007

ZADRA, C. C. P. S. Trabalho infantil: contextualização e análise comparativa das avaliações do programa de erradicação do trabalho infantil - Peti. Programa de Pós-Graduação em Desenvolvimento Econômico, do Setor de Ciências Sociais Aplicadas, do Departamento de Economia. Dissertação de Mestrado (Título de Mestre 
em Desenvolvimento Econômico). Universidade Federal do Paraná - UFPR. Curitiba - PN, 2008

Enviado: Agosto, 2019.

Aprovado: Fevereiro, 2020. 